Grand Valley State University

ScholarWorks@GVSU

Spring 1999

\title{
The Effects of an Interactive Multimedia Program on Teachers' Understanding and Implementation of an Inclusive Practice
}

Joseph B. Fisher

Grand Valley State University, fisherj@gvsu.edu

Donald D. Deshler

University of Kansas

Jean B. Schumaker

University of Kansas

Follow this and additional works at: https://scholarworks.gvsu.edu/coe_articles

Part of the Education Commons

\section{ScholarWorks Citation}

Fisher, Joseph B.; Deshler, Donald D.; and Schumaker, Jean B., "The Effects of an Interactive Multimedia Program on Teachers' Understanding and Implementation of an Inclusive Practice" (1999). Peer Reviewed Articles. 2.

https://scholarworks.gvsu.edu/coe_articles/2

This Article is brought to you for free and open access by the Education at ScholarWorks@GVSU. It has been accepted for inclusion in Peer Reviewed Articles by an authorized administrator of ScholarWorks@GVSU. For more information, please contact scholarworks@gvsu.edu. 
Winner of CLD's 1997 Award for Outstanding Research

The following article was selected by CLD's Research Committee as the winner of the 1997 Award for Outstanding Research. Presented annually, the award is designed to promote and recognize doctoral or master's level research conducted within the last five years.

Winners receive a certificate and a cash award during the Distinguished Lecture at the International Conference on Learning Disabilities sponsored by the Council for Learning Disabilities. Joseph B. Fisher received his award on Saturday, October 25, 1997, during CLD's 19th International Conference in Arlington, Virginia.

\title{
THE EFFECTS OF AN INTERACTIVE MULTIMEDIA PROGRAM ON TEACHERS' UNDERSTANDING AND IMPLEMENTATION OF AN INCLUSIVE PRACTICE
}

\author{
Joseph B. Fisher, Donald D. Deshler, \\ and Jean B. Schumaker
}

\begin{abstract}
The effects of an interactive multimedia program on teachers' understanding and implementation of an inclusive practice were examined. Fifty-eight preservice teachers and 10 inservice teachers were randomly assigned to one of two teacher development programs. The first, called the Virtual Workshop, was a computer-based, interactive multimedia program. The second, called the Actual Workshop, was a traditional, live, presenter-directed program. Results indicated that compared to their pretest scores, the posttest scores earned by participants on the tests of knowledge and understanding of the inclusive practice significantly improved after participation in both workshops. No statistically significant difference was found between the posttest scores earned by teachers in the two groups. Moreover, satisfaction ratings of both workshops were favorable. Also, inservice teachers who participated in the two workshops correctly performed a substantially greater number of the practice's targeted behaviors after training than before training. This study suggests that the Virtual Workshop may provide a new medium through which effective teacher development can be provided.
\end{abstract}

JOSEPH B. FISHER, Ph.D., is Assistant Professor, Grand Valley State University.

DONALD D. DESHLER, Ph.D., is Director, University of Kansas Center for Research on Learning. JEAN B. SCHUMAKER, Ph.D., is Associate Director, University of Kansas Center for Research on Learning. 
The students in America's classrooms are becoming increasingly diverse (Hodgkinson, 1991). This diversity is not only ethnic, cultural, and economic, but also academic. One factor contributing to the increase in academic diversity has been the movement to include students with learning disabilities within general education classrooms for most if not all of the school day (Gartner \& Lipsky, 1987; Kauffman, 1994; Will, 1986).

Although practices designed to improve the achievement of students with learning disabilities in inclusive classes have been developed and validated (Fisher, Schumaker, \& Deshler, 1995), teacher development programs have not proved successful in translating such instructional innovations into classroom practice on a broad scale (Gersten, Vaughn, Deshler, \& Schiller, 1995; Malouf \& Schiller, 1995). Often, these programs involve one-shot sessions (Kline, Deshler, \& Schumaker, 1992), focus on practices frequently not perceived as needed by teachers (Fullan with Stiegelbauer, 1991), provide few, if any, opportunities to practice and receive feedback (Cruickshank \& Metcalf, 1990), and offer little or no follow-up classroom support (Hoover \& Boethel, 1991).

Such episodic teacher development programs contrast directly with more successful comprehensive teacher development programs that are needs-based, participant-owned, and supported over time (Schumaker \& Clark, 1990; Showers, Joyce, \& Bennett, 1987). Comprehensive programs are more expensive than episodic programs (Korinek, Schmid, \& McAdams, 1985) and may be beyond the means of today's public schools. Clearly, if general education teachers are going to more successfully address the educational needs of all students enrolled in academically diverse classrooms, improving teacher development programs in ways that facilitate teachers' adoption of validated inclusive practices in cost-effective ways must be found.

One emerging technology that eventually might be used to provide teacher development programs is interactive multimedia. Interactive multimedia is a term used to describe computer-based programs that provide users random access to multiple forms of media (i.e., text, graphics, audio, video, etc.) about a particular topic (e.g., Kinzie \& Berdel, 1990; Marchionini, 1988).

Availability of interactive multimedia programs for teacher development could shift the balance from less effective episodic education programs to more effective comprehensive ones. For example, a library of CDROM-based, interactive multimedia programs on innovative practices could be provided to teachers. From such a library, teachers could choose programs on those innovative practices that would fit their most pressing instructional needs. While using a chosen interactive multimedia program, teachers could practice using the innovation in a simulated lesson and receive feedback on their performance. Moreover, a teacher could review the program as frequently as desired.

Additionally, interactive multimedia programs could afford school districts the option of bringing new teachers up to speed with other staff in a relatively short time because the new teacher would have immediate access to the required training. That is, they would not have to wait for the next "formal" training session. Finally, because CD-ROM-based, interactive multimedia programs can be distributed with great ease through the mail, professionals would have timely access to state-of-the-art instructional innovations.

These potential advantages make interactive multimedia programs attractive for providing teachers of academically diverse groups of students training in effective inclusive practices. Not surprisingly, numerous interactive multimedia programs for university students and professionals have been developed on a broad array of subjects including accounting (Becker \& Dwyer, 1994), art (Covey, 1990), biology (Hannaway, Shuler, Bolte, \& Miller, 1992; Hutchings, Hall, \& Thorogood, 1994; Jaffe \& Lynch, 1989), business (Acovelli \& Nowakowski, 1994), foreign language (Liu \& Reed, 1995), history (Chignell \& Lacy, 1988; Spoehr \& Spoehr, 1994), literature (Landow, 1989), medicine (Lee, Ault, Kirk, \& Comstock, 1995), and statistics (Egan et al., 1989; Harding, Lay, Moule, \& Quinney, 1995; Johnson \& Grover, 1993).

Nevertheless, despite the promise these programs hold, no methodologically sound empirical studies have examined the effects of interactive multimedia programs on the professional development of classroom teachers. Moreover, except for a study by Shyu and Brown (1992) on origami, no studies have examined the effect of interactive multimedia programs on adults' ability to use what they have learned on an authentic task, such as teaching a lesson to a classroom of students.

If interactive multimedia programs are going to be used to prepare teachers to address the educational needs of students with learning disabilities in general education classrooms, studies must be conducted to determine whether such programs (a) are effective with regard to teaching preservice and inservice teachers new knowledge about inclusive practices; (b) are effective with regard to teaching teachers to implement inclusive practices in their classrooms; and (c) are efficient with regard to cost.

The purpose of this study was to directly address the first two of these issues and to shed light on the third. For this study, two comprehensive teacher development 
programs were created for an inclusive practice called the Concept Mastery Routine (Bulgren, Schumaker, \& Deshler, 1993). The effects of these two programs on preservice and inservice teachers' knowledge of and skill in implementing the practice were measured and compared, and the costs of developing the hypermedia program were outlined. The first program, called the Virtual Workshop, was a computer-based hypermedia program. The second program, called the Actual Workshop, was a traditional, live, presenter-directed program.

\section{METHODS}

\section{Participants}

Preservice teachers. Fifty-eight university students volunteered to participate in the study. These students were recruited from a group of 58 students enrolled in an instructional methods course. Of these students, 39 were undergraduates and 19 were graduates; 22 were earning elementary teaching certificates, 34 were earning secondary teaching certificates, and 2 were seeking no certification; 44 were female and 14 were male; and 53 were white, 3 were Asian, and 2 were Hispanic. The students' ages ranged from 20 to 42 years $(M=23.86$, $S D=4.33$ ). For participating, each student received $\$ 25$ and a copy of the Concept Mastery Routine teacher's manual (Bulgren et al., 1993).

Inservice teachers. Ten inservice teachers volunteered to participate in the study. Of these teachers, eight were general education teachers (grades 7-12), and two were special educators (grade 7). These teachers were recruited from five schools in a suburban school district in eastern Kansas. All held Bachelor's degrees, and three held Master's degrees. Seven were female, and 3 were male. All were white. These teachers' ages ranged from 23 to 57 years $(M=35.80, S D=$ $11.18)$, and their years of teaching experience ranged from .50 to $24(M=8.80, S D=9.77)$. For participating, each inservice teacher received $\$ 50$ and a copy of the Concept Mastery Routine teacher's manual (Bulgren et al., 1993).

\section{Setting}

Virtual workshop. The Virtual Workshop took place in a classroom at a large midwestern university. The classroom was outfitted with 10 seats arranged in a half circle facing a large-screen television monitor that was connected to a computer. This classroom was adjacent to a Macintosh ${ }^{\mathrm{TM}}$ computer lab.

Actual workshop. The Actual Workshop took place at the same university in a similar classroom. This classroom was outfitted with 10 seats arranged in a half circle facing an overhead projector, a projector screen, and a large-screen television monitor connected to a videotape player.

\section{The Concept Mastery Routine}

The Concept Mastery Routine (Bulgren et al., 1993) is a set of instructional procedures designed to help teachers teach academically diverse classes of students to understand and master information related to key concepts (e.g., democracy, mammal, rhombus) found in the curriculum. The routine is comprised of a threephase instructional sequence. In phase one, called "Cue," teachers provide students an advance organizer during which they explain that a concept is going to be learned, how it is going to be learned, and how students are to participate. In phase two, called "Do," students learn about the concept by completing a Concept Diagram (see Figure 1) in partnership with the teacher. A Concept Diagram is a two-dimensional graphic device comprised of seven sections. Each section is completed with specific information about the concept. Teachers and students complete the Concept Diagram following seven Linking Steps. The Linking Steps are procedures a teacher follows to ensure the Concept Diagram is completed accurately and in partnership with students. Once the Concept Diagram has been completed, phase three begins. In this phase, called "Review," teachers ask students questions to check their understanding of the concept and the process followed to analyze the concept.

\section{Teacher Development Programs}

Virtual workshop. Two teacher development programs were prepared to teach inservice and preservice teachers to use the Concept Mastery Routine. One, the Virtual Workshop, was a computer-based, hypermedia program created using the software programs Authorware $^{\mathrm{TM}}$ (Macromedia, Inc.) and Premier ${ }^{\mathrm{TM}}$ (Adobe, Inc.). The Virtual Workshop was stored on a recordable compact disc. Organized like a book, the content for the Virtual Workshop was comprised of nearly 100 "electronic" pages. These pages were grouped into six chapters, and the chapters were grouped into four sections. The titles for these sections and chapters were listed in a table of contents that was always present along the right-hand quarter of the computer screen. Using a mouse, a teacher could select any section or chapter, at any time and as often as wanted, by "clicking" its title. Upon doing so, information about the selected section or chapter appeared in the presentation window-the remaining three-quarters of the screen. This information was in the form of text, video, audio, animated graphics, or a combination of these media. For example, immediately after clicking on Chapter 2 from the table of contents, the chapter's title, "The Linking Steps," appeared in the center of the presentation window, and a narrator's voice provided an advance organizer about the chapter's contents. 
Following this advance organizer, the chapter's first page appeared in the presentation window. This page contained a brief passage of text describing the first Linking Step. Imbedded within this passage were several blue bold-faced words. Unlike other words, these words, called hypertext, could be clicked by moving the cursor to the word and pressing down once on the mouse. When clicked, additional information about that word appeared in the presentation window.

In addition to text, the page also contained a video segment showing a teacher performing the first Linking Step with students, which could be played over and over again. To electronically control the video segments, a "remote control" was present on the computer screen. Areas on this remote control could be clicked to either play, rewind, fast forward, or pause the video segment.

To enable the learner to electronically turn the chapter's pages, four arrows were present in the lower righthand corner of the computer screen. The right-pointing arrow could be clicked to turn to the chapter's next page, while the left-pointing arrow could be clicked to turn to a previous page. The remaining arrows could be clicked to turn immediately to either the chapter's first or last page.

Like the first page, all but the last page in Chapter 2 contained text describing a particular Linking Step, hypertext, and a video segment. The last page, designed to check teachers' understanding of Chapter 2, contained three multiple-choice questions, which could be answered by clicking one of three options. If a question was answered correctly, a star appeared next to it. If a question was answered incorrectly, corrective feedback was provided, and the person was prompted to answer the question again. Once all three questions on the page were answered correctly, a checkmark appeared in the table of contents next to the title for Chapter 2 to indicate that the chapter had been successfully completed.

The format of each remaining section and chapter of the Virtual Workshop followed a structure similar to that of Chapter 2. In these sections and chapters, teachers learned about other components of the Concept Mastery Routine, practiced completing sample Concept Diagrams, studied the validation research, and examined numerous Concept Diagrams constructed by other

Figure 1. Concept diagram.

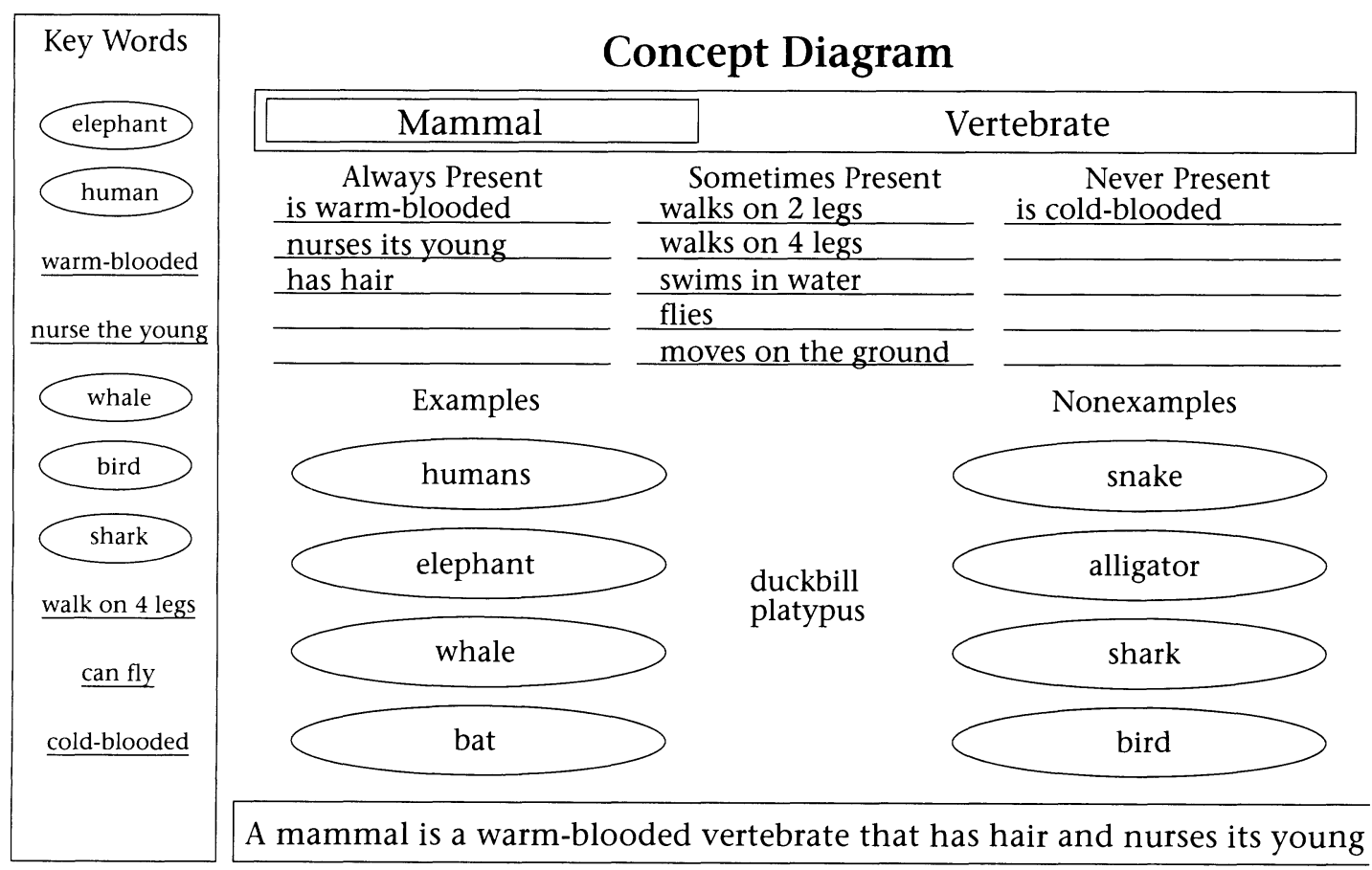


teachers. Also, teachers practiced making decisions about the use of the Concept Mastery Routine in a scenario-based simulation. That is, participants read a scenario describing a lesson in which the routine was to be used with students. At designated points in the scenario, a multiple-choice question asking participants to decide how to apply the routine was presented. Once the question was answered correctly, participants were allowed to continue through the scenario. If participants answered the question incorrectly, corrective feedback was provided and they were allowed to attempt answering the question again.

The Virtual Workshop integrated many of the known principles of effective teacher development (Schumaker \& Clark, 1990; Showers et al., 1987; Stallings, 1989). For example, teachers were provided: (a) rationales that explained why the routine should be used; (b) a thorough description of the routine; (c) several models demonstrating how to use the routine in a classroom lesson; (d) the opportunity to practice constructing Concept Diagrams and to receive corrective feedback; and (e) the opportunity to practice answering questions about how to apply the routine in a simulated lesson and to receive feedback. Also, as will be described later, following the Virtual Workshop, participating inservice teachers made a written commitment to apply the routine.

The development the CD-ROM containing the Virtual Workshop cost an estimated $\$ 40,800$. Costs were accrued in four primary areas: $\$ 12,810$ for hardware; $\$ 5,490$ for software; $\$ 18,000$ for personnel; and $\$ 4,500$ for video production.

Actual workshop. The second teacher development program was called the "Actual Workshop." Unlike the Virtual Workshop, the Actual Workshop followed a more traditional format; it was done live and was presenter-directed, not user-directed. That is, the content of the Actual Workshop was presented by a live expert using a lecture format. For example, when teaching about the Linking Steps, the presenter first stated an advance organizer. Then he displayed and summarized an overhead transparency describing the first Linking Step. Next, a video segment of a teacher performing the first Linking Step was shown on a monitor. Then the presenter described the remaining six Linking Steps in the same manner. Finally, three multiple-choice questions were presented. Teachers answered them independently, received the correct answers, and were asked if clarification was needed. Once the Linking Steps had been covered, the presenter proceeded to other content. Since a presenter was directing the Actual Workshop, if a teacher wanted to spend additional time reviewing the Linking Steps, he/she could not. Additionally, after learning about the Linking Steps, a teacher could not proceed to content of his/her choice. No part of the presentation was presented more than once; however, any questions participants asked were answered.

The content covered in the Virtual Workshop was also covered in the Actual Workshop. Moreover, the content of the Actual Workshop was organized according to the Virtual Workshop's table of contents. To help ensure consistency across workshops, each page of the Virtual Workshop, including chapter questions, sample Concept Diagrams, and validation research data, was downloaded and printed as overhead transparencies for the Actual Workshop. Moreover, all the video segments shown in the Virtual Workshop were integrated into the Actual Workshop. Finally, like students in the Virtual Workshop, students in the Actual Workshop practiced completing sample Concept Diagrams and practiced making decisions about how to use the routine in a scenario-based simulation.

To check content consistency across the two workshops, a content checklist was created and was completed by an independent rater for both the Virtual and Actual Workshops. The rater completed the Virtual Workshop on the computer and attended an Actual Workshop. Findings indicate that $97.6 \%$ of the content presented in the two workshops was the same.

The development cost of the Actual Workshop was an estimated $\$ 9,290$. These costs were accrued in the same four areas as the Virtual Workshop: $\$ 1,895$ for computer hardware; $\$ 395$ for computer software; $\$ 3,000$ for personnel; and $\$ 4,500$ for video production.

\section{Measurement Instruments}

Knowledge test. A set of seven short-answer questions was developed to test participants' understanding of the Concept Mastery Routine. The questions related to teachers' understanding of the Concept Mastery Routine's components and procedures. The instructions indicated that participants had 30 minutes to answer the questions and that only the content of each answer would be scored, not spelling, grammar, or punctuation.

To score participants' answers, evaluation guidelines specifying acceptable answers for each question were developed. For five of the seven questions, participants received up to 3 points for each written answer. For Question \#2, participants received up to 3 points for the answer to each of the question's three parts. For Question \#3, participants received up to 2 points for the answer to each of the question's seven parts. Unacceptable answers were awarded zero points. Participants could earn a maximum score of 38 points. Once a point value had been assigned to each answer, the points were totaled, divided by 38 , and multiplied by one hundred, producing a percentage score. This percentage score was called the Knowledge Score. 
Diagram test. For this test, participants filled in a Concept Diagram for a familiar concept, automobile. This measure was developed to test participants' knowledge of what type of information (e.g., characteristic, example, etc.) belonged in each of the Concept Diagram's sections. Participants were allowed $10 \mathrm{~min}-$ utes to complete the 26 blanks on the diagram and were told that only the content of their written responses would be scored, not spelling, grammar, or punctuation.

To score participants' completed Concept Diagrams, evaluation guidelines specifying acceptable responses were developed. For 21 of the Concept Diagram's 26 blanks (e.g., Always Characteristics, Nonexamples, Definition, etc.), participants received 5 points for each acceptable response. For the remaining blanks (e.g., Key Words), participants received 1 point for each acceptable response. All unacceptable responses were awarded zero points. Each participant could earn a maximum of 110 points. Once a point value had been assigned to each section, the points were totaled, divided by 110 , and multiplied by one hundred, producing a percentage score. This percentage score was called the Diagram Score.

Implementation checklist. An observational checklist was developed to assess some participants' implementation of the Concept Mastery Routine during a classroom lesson. The checklist was comprised of three sections which corresponded to the routine's Cue-DoReview Sequence. Using section one, observers checked teachers' use of behaviors associated with introducing or "Cueing" the routine (e.g., gaining students' attention). Using section two, observers checked teachers' use of behaviors associated with "Doing" a Concept Diagram with students (e.g., naming the targeted concept). Finally, using section three, observers checked teachers' use of behaviors associated with "Reviewing" the concept (e.g., asking procedural questions). A total of 39 teacher behaviors were assessed. For 24 of these behaviors, teachers received 5 points per behavior when it was performed. Regarding the remaining 15 behaviors, teachers received 1 point when each was performed. If any behavior was not performed, the teacher received zero points on the checklist for that behavior. Additionally, each time the teacher interacted with a student in conjunction with one of the 38 behaviors, an additional point, up to 20 points in total, was awarded. Each time the Concept Mastery Routine was used, teachers could earn 155 points on the checklist. Once a point value had been assigned to each behavior on the checklist by an observer, the points were totaled, divided by 155 , and multiplied by one hundred, producing a percentage score. This percentage was called the Implementation Score.
To guide observers' use of the checklist, observational guidelines were developed, objectively defining each behavior and specifying how points on the checklist were to be awarded. The observers practiced scoring videotaped presentations of the routine until the observers agreed on at least $90 \%$ of their recordings on the checklist.

Satisfaction questionnaire. A 14-item questionnaire was developed to assess participants' satisfaction with the training they received. Each questionnaire item included a 7-point Likert-type scale ranging from "disagree" (1) to "agree" (7). The items were designed to determine (a) how enjoyable participants found the training; (b) how engaged participants felt during the training; (c) how understandable participants found the content; and (d) how applicable participants found the content. Teachers' ratings for these items were called the Satisfaction Scores.

Reliability. Interscorer reliability was determined by having two scorers independently score $20 \%$ of the Knowledge Tests and Diagram Tests. Interscorer reliability for the Implementation Checklist was determined by having two observers simultaneously record information in $20 \%$ of the classroom observations of teachers' implementation of the routine. The points awarded by the two observers were compared item by item for each of the measures. The percentage of agreement was calculated by dividing the number of agreements by the number of disagreements and multiplying by 100 . For the Knowledge Tests, the scorers agreed 1,397 times out of 1,444 opportunities to agree (total percentage of agreement $=96.75 \%$ ). For the Diagram Tests, the scorers agreed 967 times out of 988 opportunities to agree (total percentage of agreement $=$ $97.87 \%)$. For the Implementation Checklists, the scorers agreed 1,979 times out of 2,040 opportunities to agree (total percentage of agreement $=97.01 \%$ ).

\section{Virtual Workshop Procedures}

Preservice teachers. Twenty-nine of the 58 preservice teachers were randomly assigned to the Virtual Workshop group. In groups of 10 or fewer, these preservice teachers participated in a Virtual Workshop on the Concept Mastery Routine. Immediately before the Virtual Workshop, a session leader pretested the preservice teachers on the Knowledge and Diagram Tests. Participants were allowed a maximum of 30 minutes to complete the Knowledge Test and a maximum of 10 minutes to complete the Diagram Test. If participants asked about a question's answer, they were instructed to answer the question as best they could. Next, using a computer attached to a large-screen monitor, the session leader loaded the Virtual Workshop and provided a 5-minute demonstration of how to "page" or navigate through the computer program. Following this demonstration, the 
preservice teachers were escorted to an adjacent computer lab. Each participant then selected a computer on which the Virtual Workshop was loaded and began to navigate the program. The preservice teachers were provided a maximum of two and a half hours to navigate the entire program. The session leader remained in the lab to provide technical support (e.g., restart frozen computers, adjust computer volume, change broken CD-ROM drives). If preservice teachers had questions about content, they were told the computer program contained all the information they needed to understand the Concept Mastery Routine. Once the preservice teachers had completed the Virtual Workshop, they were administered the Knowledge Test, Diagram Test, and Satisfaction Questionnaire. Again, they were provided a maximum of 30 minutes for the Knowledge Test and 10 minutes for the Diagram Test. No time limit was set for completing the Satisfaction Questionnaire. A total of four hours were scheduled for the preservice teachers to complete the pretests, the Virtual Workshop, and the posttests.

Inservice teachers. Of the 10 inservice teachers, five were randomly assigned to the Virtual Workshop treatment group. These four general education teachers and one special education teacher participated in the Virtual Workshop on the Concept Mastery Routine following the same procedures as those used with preservice teachers. However, before participating, the four general education teachers were observed delivering three or more lessons in their classrooms. During these lessons, each participating teacher delivered instruction on a concept of his/her choice. During each lesson, observers scored the general education teachers' presentation using the Implementation Checklist. Once the baseline data were stable or showed decreasing trends for each of these teachers, they participated in the Virtual Workshop on the Concept Mastery Routine. Afterwards, these four general education teachers were again observed presenting lessons in which they indicated a concept would be taught. During each lesson, observers again scored the teachers' presentation using the Implementation Checklist. The special education teacher was not observed teaching concepts and did not implement the routine. This teacher taught at a school with several of the participating general educators, and she wanted to learn about the routine the general educators were going to use in classes in which her mainstreamed special education students were enrolled.

\section{Actual Workshop Procedures}

Preservice teachers. Twenty-nine preservice teachers were randomly assigned to the Actual Workshop treatment group. Like the preservice teachers assigned to the Virtual Workshop treatment group, these preservice teachers attended the Actual Workshop in groups of 10 or fewer and were initially pretested on the Knowledge and Diagram Tests. Once the pretests were completed, a session leader began the Actual Workshop. Using overhead transparencies, an overhead projector, videotape segments, and a videotape player attached to a largescreen monitor, the session leader directed the Actual Workshop. Any questions asked about the Concept Mastery Routine were answered. Once all the content had been covered, all activities had been completed, and all questions had been answered, each preservice teacher was administered the Knowledge Test, Diagram Test, and Satisfaction Questionnaire. Following the same timeline as the Virtual Workshop, a total of four hours were scheduled for completion of the pretests, the Actual Workshop, and the posttests.

Inservice teachers. Five inservice teachers were randomly assigned to the Actual Workshop treatment group. These four general education teachers and one special education teacher participated in the Actual Workshop on the Concept Mastery Routine following the same procedures as those used with preservice teachers. Moreover, like the general education teachers in the Virtual Workshop treatment group, before and after training in the Concept Mastery Routine, these inservice teachers were observed in their classrooms presenting lessons in which they indicated a concept would be taught. Observers scored these lessons using the Implementation Checklist. Again, like the special education teacher attending the Virtual Workshop, this special education teacher taught at a school with several of the participating general educators. She wanted to learn about the routine the general educators were going to use in classes in which her mainstreamed special education students were enrolled. She did not implement the routine.

\section{Experimental Designs}

Three experimental designs were employed simultaneously during this study. A pretest-posttest controlgroup design (Campbell \& Stanley, 1963) was used to compare the Knowledge Scores and Diagram Scores of preservice teachers participating in the Virtual and Actual Workshops and of inservice teachers in both workshops. A posttest-only control-group design (Campbell \& Stanley, 1963) was used to compare the Satisfaction Scores of preservice teachers participating in the Virtual and Actual Workshops, and of inservice teachers in both workshops. Finally, to determine the effects of the workshops on inservice teachers' Implementation Scores, a multiple-baseline acrossteachers design (Baer, Wolf, \& Risley, 1968) was employed and replicated twice.

\section{RESULTS}

\section{Preservice Teachers}

Listed in Table 1 are the mean percentage scores and standard deviations summarizing the pretest and 
Table 1

\section{Preservice Teachers' Mean Percentage Scores for Pretest and Posttest Knowledge and Diagram Tests by Treatment Group}

\begin{tabular}{lcccc} 
& \multicolumn{2}{c}{ Knowledge Scores } & \multicolumn{2}{c}{ Diagram Scores } \\
\cline { 2 - 4 } & Pretest & Posttest & Pretest & Posttest \\
Treatment Group & & & & $84.76 \%$ \\
Virtual Workshop & $.90 \%$ & $49.09 \%$ & $10.03 \%$ & 10.92 \\
$M$ & .67 & 6.46 & 7.47 & $84.14 \%$ \\
$S D$ & & & & $8.3 \%$ \\
Actual Workshop & $2.3 \%$ & $53.99 \%$ & 6.69 & 11.44 \\
$M$ & .90 & 6.31 &
\end{tabular}

posttest performances of preservice teachers from both treatment groups on the Knowledge and Diagram Tests. To compare the differences between these pretest and posttest scores within each treatment group, $t$-tests were performed and indicated that (a) the posttest scores of preservice teachers who participated in the Virtual Workshop were significantly higher than their pretest scores on the Knowledge Test $(t(28)=15.35$, $p<0.00)$ and the Diagram Test $(t(28)=37.99, p<0.00)$; and (b) the posttest scores of preservice teachers who participated in the Actual Workshop were significantly higher than their pretest scores on the Knowledge Test $(t(28)=17.05, p<0.00)$ and the Diagram Test $(t(28)=$ $38.70, p<0.00)$

To determine whether the two training methods had differential effects on the preservice teachers' performance, analyses of covariance (ANCOVA) were employed using the preservice teachers' posttest scores as the dependent variable and their pretest scores as the covariate. These analyses revealed no statistically significant difference between the posttest scores that preservice teachers in the Virtual and Actual Workshops earned on the Knowledge Test $(F(1,55)=0.44, p<$ $0.51)$ or the Diagram Test $(F(1,55)=0.00, p<0.98)$.

Figure 2 depicts the results from the Satisfaction Questionnaire distributed to all preservice teachers who participated. Overall, preservice teachers rated both the Virtual and Actual Workshops favorably. Across all 14 Likert-scale items, mean Satisfaction Scores ranged from 5.10 to 6.14 for preservice teachers participating in the Virtual Workshop and from 4.93 to 6.66 for preservice teachers participating in the Actual Workshop. To illuminate differences between the mean Satisfaction Scores of each treatment group for each item, analyses of variance (ANOVA) were performed.
Results indicated that teachers who participated in the Actual Workshop rated questionnaire items \#1 $(F(1,56)$ $=8.38, p<0.01), \# 5(F(1,56)=5.09, p<0.03)$, and \#9 $(F(1,56)=5.72, p<0.02)$ significantly higher than preservice teachers who participated in the Virtual Workshop. Interestingly, each of these three items pertained to how well the preservice teachers thought they understood the content presented. No significant differences emerged on the remaining questionnaire items.

\section{Inservice Teachers}

Listed in Table 2 are the mean percentage scores and standard deviations summarizing the pretest and posttest performances of inservice teachers from both treatment groups on the Knowledge and Diagram Tests. The differences between these pretest and posttest scores within each treatment group were compared using Wilcoxon Signed Ranks Tests. These analyses indicated (a) the posttest scores of inservice teachers who participated in the Virtual Workshop were significantly higher than their pretest scores on the Knowledge Test $(z=2.19, p<0.04)$ and on the Diagram Test $(z=2.19, p<0.04)$; and (b) the posttest scores of inservice teachers who participated in the Actual Workshop were significantly higher than their pretest scores on the Knowledge Test $(z=2.21, p<0.04)$ and on the Diagram Test $(z=1.80, p<0.04)$.

Though both treatments produced significant improvement, to identify possible differential effects of the two training methods on inservice teachers' Knowledge and Diagram Scores, Kruskal-Wallis OneWay Analyses of Variance by Ranks (KWANOVA) were used. These analyses revealed no significant differences between the pretest scores of teachers participating in the Virtual and Actual Workshops on the Knowledge Test $\left(X^{2}(1, N=10)=0.05, p<0.83\right)$ and the Diagram 


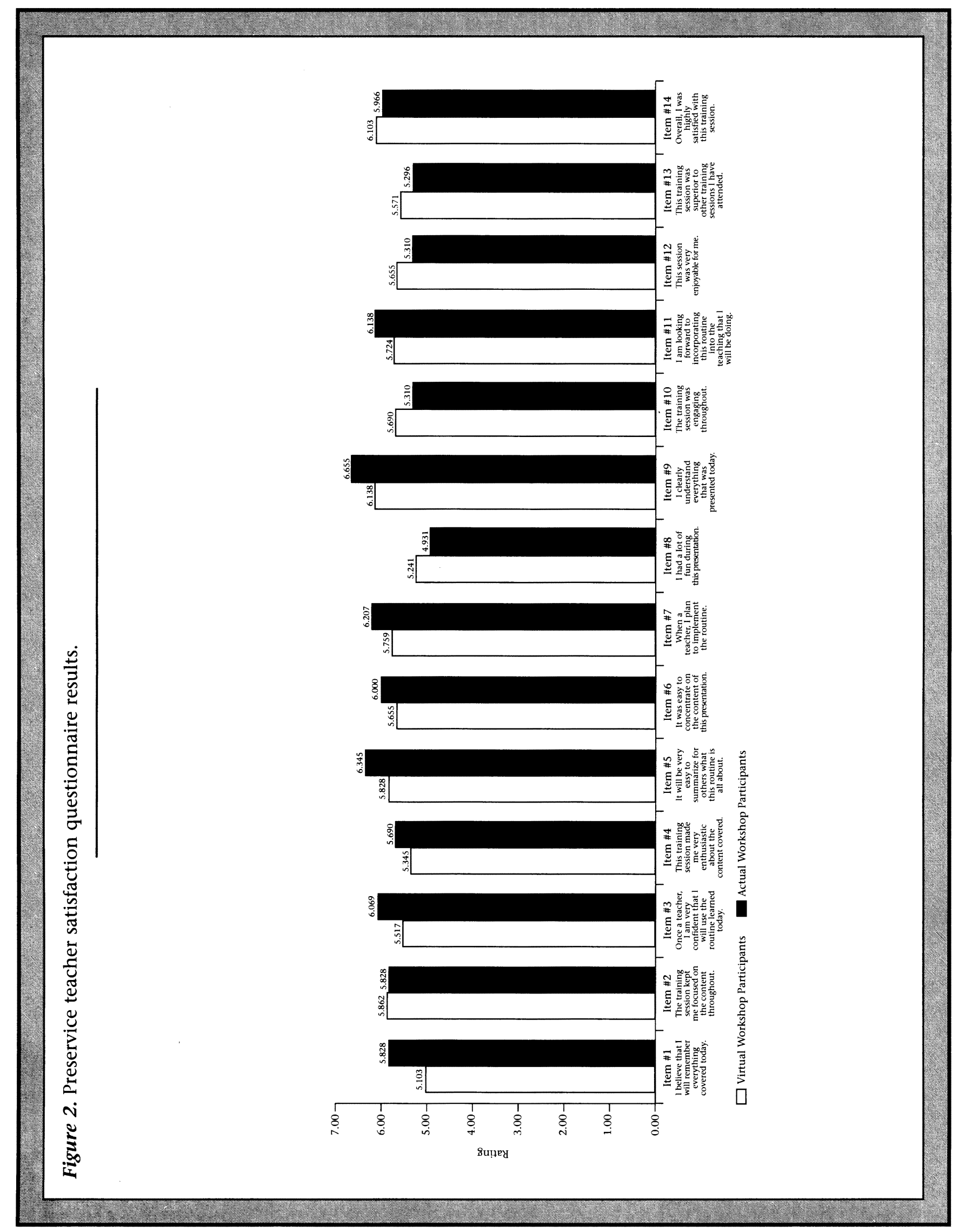

Volume 22, Spring 1999135 
Table 2

Inservice Teachers' Mean Percentage Scores for Pretest and Posttest Knowledge and Diagram Tests by Treatment Group

\begin{tabular}{llcc} 
& \multicolumn{2}{c}{ Knowledge Scores } & \multicolumn{2}{c}{$\begin{array}{c}\text { Diagram Scores } \\
\text { Preatment Group }\end{array}$} & Posttest & Pretest \\
Virtual Workshop & & & $11.81 \%$ \\
Pretest & $5.36 \%$ & $63.68 \%$ & 16.05 \\
SD & 1.23 & 4.15 & 10.95 \\
Actual Workshop & & & $39.09 \%$ \\
M & $6.32 \%$ & $60.00 \%$ & 38.18
\end{tabular}

Test $\left(X^{2}(1, N=10)=2.53, p<0.11\right)$, or between the posttest scores of these same teachers on the Knowledge Test $\left(X^{2}(1, N=10)=0.18, p<0.67\right)$ and the Diagram Test $\left(X^{2}(1, N=10)=2.22, p<0.14\right)$.

Eight of the inservice teachers were observed in their classrooms teaching concepts to their students. Figures $3,4,5$, and 6 show the performance of these teachers as recorded on the Implementation Checklist. As illustrated, during baseline, the percentage of points earned on the Implementation Checklist by teachers who participated in the Virtual Workshop ranged from $0 \%$ to $31.60 \%(M=12.45 \%, S D=9.15)$; the percentage of points earned by teachers in the Actual Workshop ranged from $3.20 \%$ to $38.06 \%(M=19.03 \%, S D=11.82)$.

After training, the percentage of points earned on the Implementation Checklist by teachers in the Virtual Workshop ranged from $73 \%$ to $92.25 \%(M=84.68 \%$, $S D=5.54$ ) (see Figures 3 and 4 ). Moreover, 10 of the 12 lessons presented by teachers after training exceeded the arbitrary mastery level of $80 \%$. The percentage of points earned on the Implementation Checklist after training by teachers who participated in the Actual Workshop ranged from $58.70 \%$ to $100 \%(M=78.25 \%$, $S D=13.27$ ) (see Figures 5 and 6 ). Of the 12 lessons presented by these teachers after training, five exceeded the mastery level of $80 \%$.

Visual examination of the Implementation Checklists suggests that teachers who participated in both the Actual and the Virtual Workshop rarely reviewed with their students what had been learned. Moreover, these teachers also did not regularly help students to discuss the characteristics possessed by examples of the targeted concept. One teacher who participated in the Actual Workshop lost some points on the Implementation Checklist because he did not always fill in the example and nonexample sections of the Concept Diagram; rather, he stated the examples and nonexamples aloud. On other occasions, teachers in both groups did not earn points because they did not provide students an adequate number of characteristics or examples of the targeted concept.

Depicted in Figure 7 are the results from the Satisfaction Questionnaire for participating inservice teachers. Overall, like the preservice teachers, the inservice teachers rated both the Virtual and Actual Workshops favorably. In fact, the mean Satisfaction Scores of the inservice teachers were even higher than those of the preservice teachers. Across all 14 Likertscale items, mean Satisfaction Scores ranged from 5.50 to 7.00 for inservice teachers who participated in the Virtual Workshop and the Actual Workshop. Analysis of the teachers' mean Satisfaction Scores using KWANOVA revealed no significant differences between the two groups on any item. Thus, what was most notable about these findings was how similarly teachers participating in the two workshops rated each item.

\section{DISCUSSION}

\section{Conclusions and Relationship to Previous Research}

The purpose of this study was to develop an interactive multimedia program and (a) to examine its effects on preservice and inservice teachers' knowledge of an inclusive practice and its effects on inservice teachers' skill in implementing the inclusive practice in their classrooms with academically diverse groups of students; and (b) to outline the costs associated with its development.

Several conclusions can be drawn from the results of this research effort. First, compared to their pretest scores, the posttest scores preservice and inservice teachers earned on the Knowledge and Diagram Tests 
Figure 3. Inservice teachers \#1 and \#2 (Virtual Workshop participants).

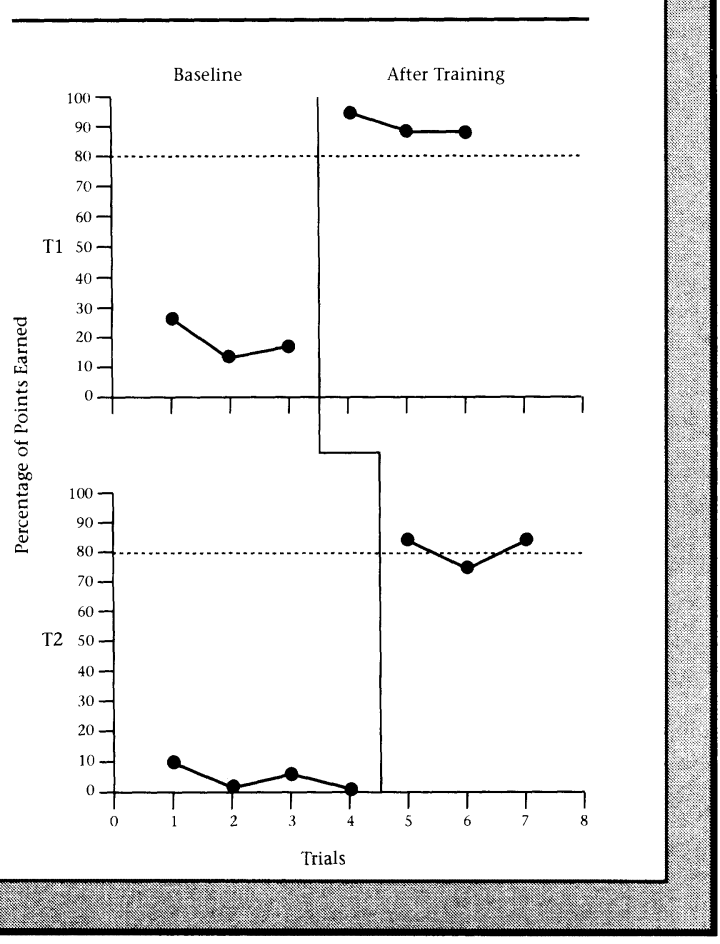

Figure 5. Inservice teachers \#5 and \#6 (Actual Workshop participants).

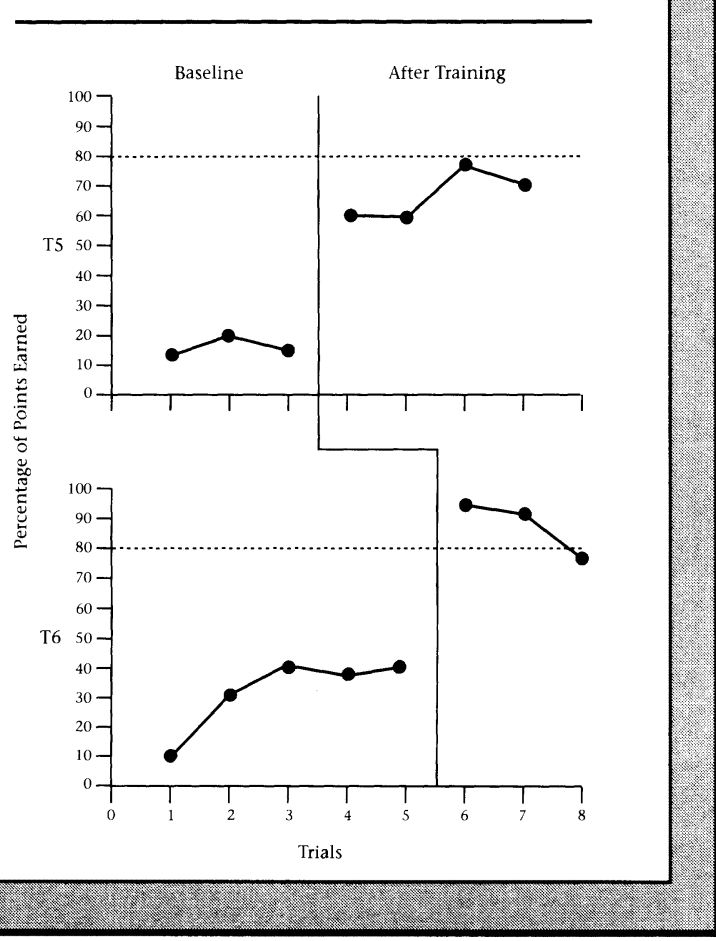

Figure 4. Inservice teachers \#3 and \#4 (Virtual Workshop participants).

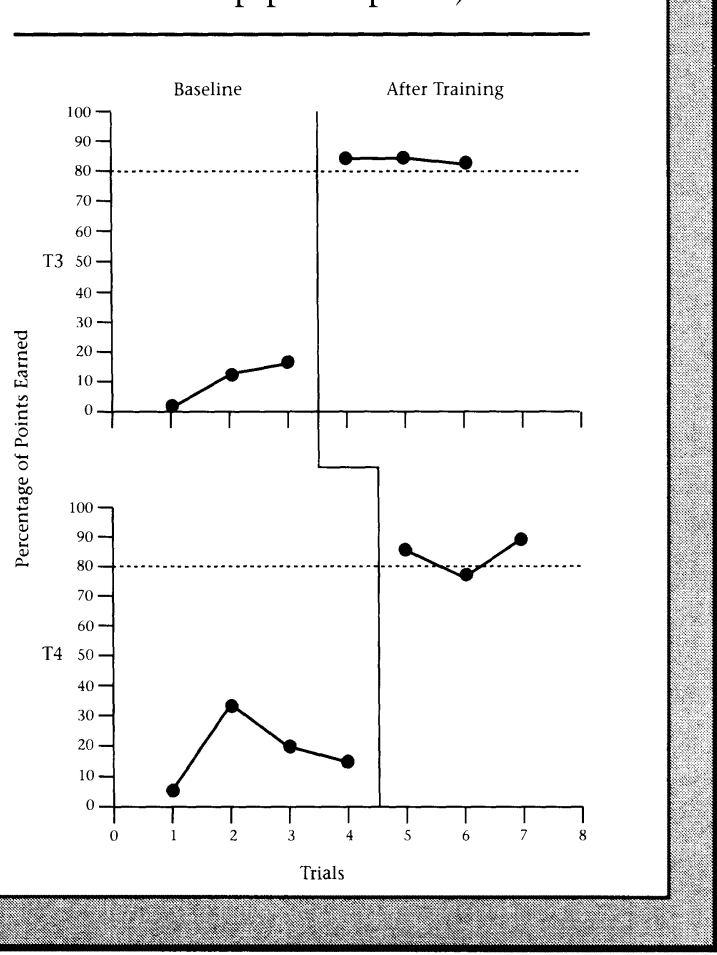

Figure 6. Inservice teachers \#7 and \#8 (Actual Workshop participants).

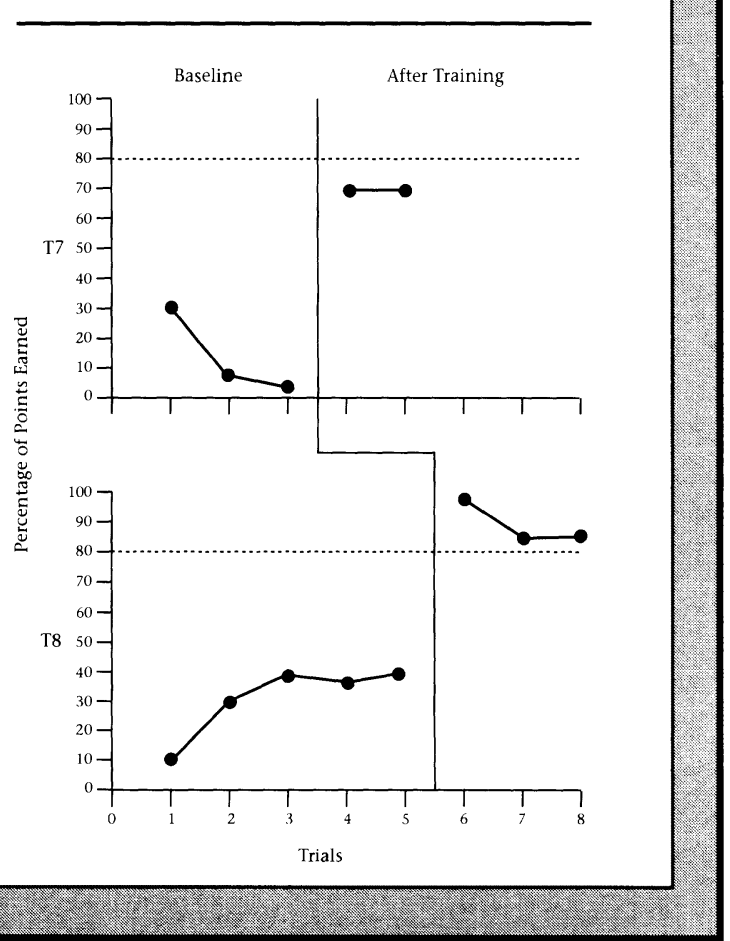




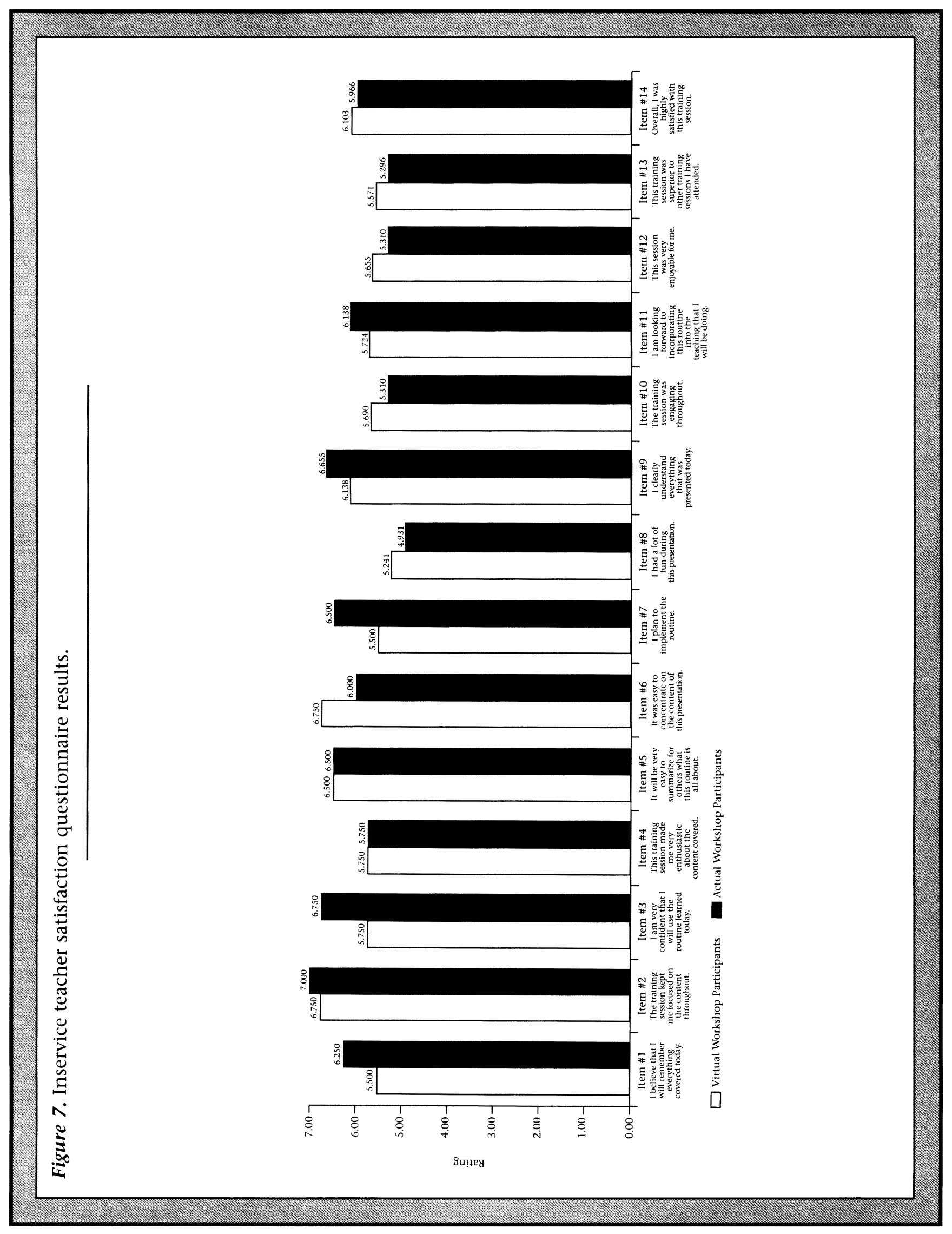


significantly improved following participation in either the Virtual or the Actual Workshop. Unfortunately, the magnitude of their improvement on the Knowledge Test was not as large as desired. That is, despite improving an average of at least 45 percentage points from pretest to posttest, preservice and inservice teachers' posttest scores on the Knowledge Test still averaged only from $49.09 \%$ to $63.68 \%$. The instruction, models, practice, and feedback these teachers received did impact their knowledge about the innovation, but the teachers' recall of information related to the Concept Mastery Routine was approximately $40 \%$ incomplete or inaccurate after training. Nevertheless, this magnitude of gain on the Knowledge Test was considerably higher than the magnitude of gain reported by other investigators utilizing interactive multimedia programs (Lanza \& Roselli, 1991; Quade, 1993; Santer et al., 1995; Schank \& Rowe, 1993)

The magnitude of the effects of both workshops on preservice and inservice teachers' performance on the Diagram Test, on the other hand, was socially significant. Overall, the teachers' average scores ranged from $84.14 \%$ to $93.63 \%$. The graphic structure of the blank Concept Diagram was designed to prompt the entry of specific content related to the targeted concept. Thus, because of the prompts the Concept Diagram provided, this test may not have been as difficult as a Knowledge Test, which required complete recall. Nevertheless, given that teachers improved, on average, at least 45 percentage points, this finding indicates that the instruction, practice, and feedback these teachers received led them to construct highly accurately Concept Diagrams.

Second, both the Virtual Workshop and the Actual Workshop had similar effects on the scores earned by preservice and inservice teachers on the Knowledge and Diagram Tests. Interestingly, other studies comparing the effects of user-directed interactive multimedia programs to computer-directed tutorials (D'Alessando et al., 1992; Hudson \& Holland, 1992) and teacher-directed lectures (Lanza \& Roselli, 1991; Quade, 1993; Santer et al., 1995; Schank \& Rowe, 1992) have contained similar findings.

Third, an analysis of the scores from the actual implementation of this innovation suggests that inservice teachers who participated in the Virtual Workshop and those who participated in the Actual Workshop performed a substantially greater number of the Concept Mastery Routine's targeted behaviors after training than before training. Moreover, these findings also suggest that, on average, inservice teachers who participated in the Virtual Workshop performed the Concept Mastery Routine in a manner similar to the teachers who participated in the Actual Workshop. This finding is important, for other studies have not measured the effect of an interactive multimedia program on adults' ability to apply a sophisticated skill in an authentic setting like a classroom. Still, despite the marked improvement of both groups with regard to teaching concepts, room remained for all participating teachers to use the routine more completely. For example, inservice teachers who participated in the Virtual Workshop rarely reviewed what had been learned with their students, did not regularly discuss what characteristics, examples, and nonexamples the targeted concept possessed, and often failed to explain to students how the routine would help them to learn.

Fourth, preservice and inservice teachers' satisfaction ratings of the Virtual and Actual Workshops were favorable. The fact that preservice and inservice teachers rated the Virtual Workshop favorably was not surprising. Interactive multimedia programs are typically well liked by their users. It was surprising, however, how favorably preservice and inservice teachers rated the Actual Workshop. In three previous studies comparing the consumer satisfaction ratings of adults who participated in group lectures and adults who participated in interactive multimedia programs, those adults who experienced the multimedia programs rated their enjoyment of the interactive multimedia programs substantially higher than those who participated in lecture (D'Alessandro et al., 1992; Hudson \& Holland, 1992; Santer et al., 1995). Interestingly, preservice teachers who participated in the Actual Workshop attained significantly higher ratings on questionnaire items pertaining to how well they understood the content presented than preservice teachers who participated in the Virtual Workshop. This finding may be cause for concern, because if Virtual Workshop participants walk away from a session feeling uncomfortable about using an innovation, they may less likely to use it. Since both groups of inservice teachers understood that the researchers would be visiting their classrooms to observe their implementation of the routine, it is unknown whether they would actually have implemented it in their classrooms if visitors had not been coming to observe.

Finally, the development cost of the Virtual Workshop was nearly four times as high as the development cost of the Actual Workshop. Still, though the development cost of the Virtual Workshop was greater, the cost to implement this workshop with teachers is less than the cost to implement the Actual Workshop. That is, each time the Actual Workshop is implemented, $\$ 250$ for the half-day presenter and $\$ 30$ for each participating teacher's half-day substitute need to be spent. Thus, the cost for 100 teachers to attend an Actual Workshop would be $\$ 3,250$. However, to implement the Virtual Workshop with one teacher could cost as little as $\$ 2.50$, 
the price of one compact disc with postage. Thus, training for 100 teachers could cost only $\$ 250.00$. Conceivably, if the number of teachers trained was increased, the cost to develop and implement the Virtual Workshop could be similar to or even less than the cost to develop and implement the Actual Workshop.

\section{Limitations}

This study is limited in several ways. First, only the inservice teachers were observed implementing the Concept Mastery Routine with students. Thus, whether preservice teachers could correctly implement the routine in an authentic setting at levels similar to the inservice teachers remains unknown.

Second, in most cases, inservice teachers who participated in either of the two workshops were observed using the routine only three times. Although the inservice teachers' scores on the Implementation Checklist were consistent, whether this level of consistency would be maintained over a semester or school year is unknown. Moreover, it is unclear whether participating teachers would continue to use the Concept Mastery Routine.

Third, all the teachers were given a pretest prior to participating in either the Virtual or Actual Workshop. This pretest may have sensitized teachers to particular content. As a result of being sensitized, their performance on the posttests and in the classroom may have been affected.

Fourth, the only instructional innovation taught to the participating preservice and inservice teachers through the Virtual Workshop was the Concept Mastery Routine. Thus, the effects of the Virtual Workshop on these teachers' performance may have resulted from the novelty of this approach. Whether these same teachers would benefit as much from participating in a second or third Virtual Workshop on other instructional innovations is unknown.

Finally, all the participants in this study were volunteers. These teachers may not be representative of the general population of preservice and inservice teachers.

\section{Future Research}

Additional research is needed before the Virtual Workshop for the Concept Mastery Routine can be used confidently in teacher development programs. Clearly, given the low posttest Knowledge Scores of inservice teachers who completed the Virtual Workshop, studies need to be conducted to examine how to improve the understanding and recall of critical content presented in interactive multimedia programs. Secondly, studies should be conducted to identify methods for improving the ability of teachers who have completed the Virtual Workshop to implement the Concept Mastery Routine more precisely. Although the teachers in the study did apply the Concept Mastery Routine with over $80 \%$ accuracy, in an earlier study (Bulgren, Schumaker, \& Deshler, 1988) teachers who completed a traditional workshop implemented the routine nearly perfectly with students on their first try. This traditional workshop differed from the Virtual Workshop in that participating teachers taught a practice lesson to one another and received corrective feedback on their instruction. In the present study, during the Virtual and Actual Workshops teachers answered questions in a scenario-based simulation only; they did not have an opportunity to practice the routine in a live simulation. Perhaps by following up the Virtual Workshop with a similar combination of practice and feedback, teachers participating in the Virtual Workshop could apply the routine nearly perfectly with students on their first try, too.

Once improvements to the Virtual Workshop are made, long-term studies in which teachers learn a series of instructional innovations using such an interactive multimedia program should be conducted. Such studies would allow investigators to determine whether the novelty of interactive multimedia impacts teachers' professional development. Moreover, such a study would enable investigators to determine whether teachers can sustain the application of newly learned innovations over time. In conjunction with this research, a costbenefit analysis could also be conducted. This analysis would more accurately reflect the true costs associated with developing and using interactive multimedia programs like the Virtual Workshop.

\section{Implications}

Interactive multimedia programs like the Virtual Workshop may have great impact on the field of teacher education. For example, at the preservice level, interactive multimedia programs could be used in place of lectures given in courses on mainstreaming methods. That is, education students could learn about different inclusive practices in a computer lab or on a home computer. Moreover, this instruction would provide a degree of depth and breadth not possible in the limited time of most university courses. In turn, course time could be used to provide preservice teachers a setting in which to practice and receive corrective feedback about an innovation learned from an interactive multimedia program. At the inservice level, teachers could choose cutting-edge inclusive practices that they want to learn, rather than attending traditional workshops about methods administrators think they should learn. These teachers could learn about cutting-edge innovations from the very best the field of education has to offer, and do so according to their own schedule. Moreover, districts could potentially provide teachers such professional development opportunities at a cost that is less per teacher than existing professional devel- 
opment models. Through such comprehensive training, teachers would be better prepared to teach their classes of academically diverse students.

\section{Summary}

The results of this study indicate that compared to their pretest scores, the posttest scores earned by inservice and preservice teachers on the Knowledge and Diagram Tests significantly improved following participation in either the Virtual or the Actual Workshop. Moreover, preservice and inservice teachers' satisfaction ratings of both workshops were favorable. Inservice teachers who participated in the Virtual Workshop and Actual Workshops correctly performed a substantially greater number of the innovation's targeted behaviors after training than before training. Overall, both the Virtual and Actual Workshops had similar, positive effects on teachers' understanding and implementation of the instructional innovation. This study suggests that interactive multimedia programs like the Virtual Workshop may provide a new medium through which effective teacher development can be provided. Potentially, this medium could provide general education teachers the training in inclusive practices they need to meet the educational needs of all students, including those with learning disabilities, in academically diverse classes.

\section{REFERENCES}

Acovelli, M., \& Nowakowski, A. (1994). The business practices course: Self-study learning reengineered. Educational Technology, 54, 21-27.

Baer, D. M., Wolf, M. M., \& Risley, T. R. (1968). Some current dimensions of applied behavior analysis. Journal of Applied Behavior Analysis, 1, 91-97.

Becker, D. A., \& Dwyer, M. M. (1994). Using hypermedia to provide learner control. Journal of Educational Multimedia and Hypermedia, 3(2), 155-172.

Bulgren, J. A., Deshler, D. D., \& Schumaker, J. B. (1993). The concept mastery routine. Lawrence, KS: Edge Enterprises.

Bulgren, J. A., Schumaker, J. B., \& Deshler, D. D. (1988). Effectiveness of a concept teaching routine in enhancing the performance of LD students in secondary-level mainstream classes. Learning Disability Quarterly, 11(1), 3-17.

Campbell, D. T., \& Stanley, J. C. (1963). Experimental and quasiexperimental designs for research. Dallas, TX: Houghton Mifflin.

Chignell, M. H., \& Lacy, R. M. (1988). Project Jefferson: Integrating research and instruction. Academic Computing, 3(2), $12-17,41-45$

Covey, P. K. (1990). Art or forgery? The strange case of Han Van Meegeren: A videodisc for aesthetics and art history. Journal of Computing in Higher Education, 2(1), 3-31.

Cruickshank, D. R., \& Metcalf, K. K. (1990). Training within teacher preparation. In W. R. Houston (Ed.), Handbook of research on teacher education (pp. 469-497). New York: Macmillan.

D'Alessandro, M. P., Galvin, J. R., Erkonsen, W. E., Albanese, M. A., Michaelsen, V. E., Huntley, J. S., McBurney, R. M., \& Easley, G. (1993). The instructional effectiveness of a radiology multimedia textbook (hyperlung) versus standard lecture. Investigative Radiology, 28(7), 643-648.
Egan, D. E., Remde, J. R., Gomez, L. M., Landauer, T. K., Eberhardt, J., \& Lochbaum, C. C. (1989). Formative design-evaluation of superbook. Transactions on Information Systems, 7(1), 30-57.

Fisher, J. B., Schumaker, J. B., \& Deshler, D. D. (1995). Searching for validated inclusive practices: A review of the literature. Focus on Exceptional Children, 28(4), 1-20.

Fullan, M. G., with Stiegelbauer, S. (1991). The new meaning of educational change (2nd ed.). New York: Teachers College Press.

Gartner, A., \& Lipsky, D. K. (1987). Beyond special education: Toward a quality system for all students. Harvard Educational Review, 57, 367-395.

Gersten, R., Vaughn, S., Deshler, D. D., \& Schiller, E. P. (1995, July). What we know (and still don't know) about utilizing research findings to improve practice: Implications for special education. Paper presented at the annual project directors meeting of the U.S. Department of Education, Office of Special Education, Washington, DC.

Hannaway, D. B., Shuler, P. E., Bolte, J. P., \& Miller, M. J. (1992). Development and evaluation of LEGUME ID: A toolbook multimedia module. Journal of Natural Resources and Life Science Education, 21(1), 57-61.

Harding, R. D., Lay, S. W., Moule, H., \& Quinney, D. A. (1995). Multimedia interactive mathematics courseware: The mathematics experience within the renaissance project. Computers and Education, 24(1), 1-23.

Hodgkinson, H. (1991). Reform versus reality. Phi Delta Kappan, 73(1), 8-16.

Hoover, W. A., \& Boethel, M. (1991). Staff development in the southwest's rural/small schools. Rural Educator, 12(2), 9-13.

Hudson, T. J., \& Holland, S. D. (1992). Interactive multimedia instruction in video production classes. Journalism Educator, 47(3), 18-26.

Hutchings, G. A., Hall, A., \& Thorogood, P. (1994). Experiences with hypermedia in undergraduate education. Computers and Education, 22(1), 39-44.

Jaffe, C. C., \& Lynch, P. J. (1989). Hypermedia for education in the life sciences. Academic Computing, 4, 10-13, 52-57, 73.

Johnson, C. W., \& Grover, P. A. (1993). Hypertutor therapy for interactive instruction. Educational Technology, 33(1), 5-16.

Kauffman, J. M. (1994). Places of change: Special education's power and identity in an era of educational reform. Journal of Learning Disabilities, 27(10), 610-618.

Kinzie, M. B., \& Berdel, R. L. (1990). Design and use of hypermedia systems. Education Technology Research and Development, 38(3), 61-68.

Kline, F. M., Deshler, D. D., \& Schumaker, J. B. (1992). Implementing learning strategy instruction in class settings: A research perspective. In M. Pressley, K. R. Harris, \& J. T. Guthrie (Eds.), Promoting academic competence and literacy in school (pp. 361-406). San Diego, CA: Academic Press.

Korinek, L., Schmid, R., \& McAdams, M. (1985). Inservice types and best practices. Journal of Research and Development in Education, 18, 33-38.

Landow, G. P. (1989). Hypertext in literacy education, criticism, and scholarship. Computers and the Humanities, 23, 173-198.

Lanza, A., \& Roselli, T. (1991). Effects of the hypertextual approach versus the structured approach on students' achievement. Journal of Computer-Based Instruction, 18(2), 48-50.

Lee, W., Ault, H., Kirk, J. S., \& Comstock, C. H. (1995). Interactive multimedia for prenatal ultrasound training. Obstetrics and Gynecology, 85(1), 135-140.

Liu, M., \& Reed, W. M. (1995), The effect of hypermedia assisted instruction on second language learning. Journal of Educational Computing Research, 12(2), 159-175. 
Malouf, D. B., \& Schiller, E. P. (1995). Practice and research in special education. Exceptional Children, 61(5), 414-424.

Marchionini, G. (1988). Hypermedia and learning: Freedom and chaos. Educational Technology, 28(11), 8-12.

Quade, A. M. (1993, January). An assessment of the effectiveness of a hypertext instructional delivery system when compared to a traditional CAI tutorial. Paper presented at the Convention of the Association for Educational Communications and Technology, New Orleans, LA.

Santer, D. M., Michaelsen, V. E., Erkonsen, W. E., Winter, R. J., Woodhead, J. C., Gilmer, J. S., D'Alessandro, M. P., \& Galvin, J. R. (1995). A comparison of educational interventions: Multimedia textbook, standard lecture, and printed textbook. Archives of Pediatric and Adolescent Medicine, 149, 297-302.

Schank, P. K., \& Rowe, L. A. (1993). The design and assessment of a hypermedia course on semiconductor manufacturing. Journal of Educational Multimedia and Hypermedia, 2(3), 299-320.

Schumaker, J. B., \& Clark, F. L. (1990). Achieving implementation of strategy instruction through effective inservice education. Teacher Education and Special Education, 13(2), 105-116.

Showers, B., Joyce, B., \& Bennett, B. (1987). Synthesis of research on staff development: A framework for future study and a state-of-the-art analysis. Educational Leadership, 45(3), 77-87.
Shyu H. Y., \& Brown, S. W. (1992). Learner control versus program control in interactive videodisc instruction: What are the effects in procedural learning. International Journal of Instructional Media, 19(2), 85-96.

Spoehr, K. T., \& Spoehr, L W. (1994). Learning to think historically. Educational Psychologist, 29(2), 71-77.

Stallings, J. A. (1989, March). School achievement effects and staff development: What are some critical factors? Paper presented at the annual meeting of the American Educational Research Association, San Francisco, CA.

Will, M. C. (1986). Educating children with learning problems: A shared responsibility. Exceptional Children, 52, 411-415.

\section{AUTHOR NOTE}

This research was supported in part by Grant \# HO23B50025 from the U. S. Department of Education, Office of Special Education to the University of Kansas.

Requests for reprints should be addressed to: Joseph B. Fisher, Advanced Studies in Education, Grand Valley State University, 301 W. Fulton, Suite 920, Grand Rapids, MI 49504. 